\title{
Use of azathioprine for nongranulomatous ulcerative jejunoileitis
}

\author{
Robert Enns MD FRCP, Thomas Lay MD FRCP, Ronald Bridges MD FRCP
}

\begin{abstract}
R Enns, T Lay, R Bridges. Use of azathioprine for nongranulomatous ulcerative jejunoileitis. Can J Gastroenterol 1997; 11(6):503-506. Nongranulomatous ulcerative jejunoileitis (NGUJI) is a rare, often fatal disorder that produces multiple nonmalignant small bowel ulcerations. A 55-year-old woman with presumed celiac disease presented with steroid-refractory diarrhea, weight loss and abdominal pain. A laparotomy was performed to exclude the possibility of a lymphomatous disorder, and multiple nonmalignant small bowel ulcerations were discovered. Despite a combination of treatment with total parenteral nutrition (TPN) and prednisone $30 \mathrm{mg} /$ day she continued to deteriorate. The addition of azathioprine to her treatment regimen resulted in marked clinical and biochemical improvement. Her enteroscopy normalized, and she was able to discontinue TPN and reduce her steroid requirements. Although azathioprine has been used occasionally to treat refractory sprue, there have been no reports of its use in NGUJI. In this case, azathioprine played a key role in the management of NGUJI and should be considered a treatment option for patients with this disorder.
\end{abstract}

Key Words: Azathioprine, Inflammatory bowel disease, Malabsorption, Nongranulomatous ulcerative jejunoileitis

\section{Recours à l'azathioprine pour la jéjuno-iléite ulcéreuse non granulomateuse}

RÉSUMÉ : La jéjuno-iléite ulcéreuse non granulomateuse est une maladie rare, souvent fatale, qui entraîne des ulcérations multiples non malignes du grêle. Une femme de 55 ans, atteinte présumément de maladie cœliaque s'est présentée pour diarrhée ne répondant pas à la corticothérapie, perte de poids et douleur abdominale. À la laparotomie, destinée à exclure le diagnostic de lymphome, on a découvert des ulcérations multiples non malignes au niveau du grêle. Malgré le traitement associatif par nutrition parentérale totale et prednisone à $30 \mathrm{mg} / \mathrm{j}$, son état a continué de se détériorer. L'ajout d'azathioprine à son schéma thérapeutique a entraîné une amélioration clinique et biochimique marquée. Son entéroscopie s'est normalisée et elle a pu poursuivre la NPT et diminuer son recours à la corticothérapie. Bien que l'azathioprine ait été utilisée à l'occasion pour traiter la sprue réfractaire, aucun rapport ne signalait son emploi dans ce type de jéjuno-iléite. Dans ce cas, l'azathioprine a joué un rôle clé dans le traitement et doit être envisagée comme option thérapeutique le cas échéant.

$\mathrm{M}$ ultiple nonmalignant ulcerations of the small bowel are rare but frequently fatal complications of celiac sprue (1). The etiology of this ulceration is unknown. Patients with nongranulomatous ulcerative jejunoileitis (NGUJI) present with gastrointestinal complications including abdominal pain, malabsorption, bleeding, and small intestinal obstruction or perforation, despite adherence to a glutenfree diet.

Therapy for this disorder includes initiation or maintenance of a strict gluten-free diet, resection of localized disease, total parenteral nutrition (TPN), and corticosteroid therapy in refractory cases. Even in patients treated aggressively, however, the mortality rate may approach $75 \%$ (2). Although cyclosporine and azathioprine have been used occasionally for the treatment of refractory sprue, they have not been used in patients with ulcerative jejunoileitis (3-5).

This paper was a winning entry in the Consultations in Gastroenterology case study competition that was initiated and funded with the generous support of Astra Canada and is endorsed by the Canadian Association of Gastroenterology

Department of Gastroenterology, University of Calgary, Calgary, Alberta

Correspondence and reprints: Dr Ronald Bridges, 415-14th Street NW, Calgary, Alberta T2N 2A1. Telephone 403-270-9555, fax 403-270-7479, e-mail bridgesy@cadvision.com 
TABLE 1

Investigations performed at diagnosis, on prednisone and on aziathioprine

\begin{tabular}{|c|c|c|c|c|}
\hline Test & At diagnosis & On prednisone & On azathioprine & Normal \\
\hline Hemoglobin (g/L) & 126 & 113 & 151 & $125-164$ \\
\hline Platelet count $\left(\times 10^{9} / \mathrm{L}\right)$ & - & 634 & 407 & $150-400$ \\
\hline Blood smear & Howell-Jolly bodies* & Howell-Jolly bodies* & Howell-Jolly bodies* & - \\
\hline Red blood cell folate $(\mu \mathrm{mol} / \mathrm{L})$ & 101 & 863 & $>396$ & $>396$ \\
\hline Folate (nmol/L) & 1.1 & 20.5 & $>45$ & $>5.7$ \\
\hline Albumin $(g / L)$ & 27 & 27 & 51 & $35-50$ \\
\hline Protein ( $\mathrm{g} / \mathrm{L})$ & 47 & 48 & 75 & $60-84$ \\
\hline Carotene $(\mu \mathrm{mol} / \mathrm{L})$ & $<0.9$ & 0.6 & 1.5 & $0.9-3.7$ \\
\hline D-xylose excretion (25 g load) (\%) & 10.9 & - & - & $25-50$ \\
\hline Vitamin $B_{12}(p m o l / L)$ & 577 & 517 & 576 & $>197$ \\
\hline Stool cultures & Negative & Negative & Negative & - \\
\hline Clostridium difficile toxin & Negative & Negative & Negative & - \\
\hline VDRL test & Negative & - & - & - \\
\hline Zinc $(\mu \mathrm{mol} / \mathrm{L})$ & - & 9.7 & - & $8.0-20.0$ \\
\hline Ferritin $(\mu \mathrm{g} / \mathrm{L})$ & - & 107 & 63 & $9-340$ \\
\hline $24 \mathrm{~h}$ fecal fat $(\mathrm{g})$ & 18.7 & - & - & $<4.27$ \\
\hline Calcium (mmol/L) & - & 2.02 & 2.36 & $2.13-2.60$ \\
\hline Gastrin (ng/L) & - & 42 & - & $0-100$ \\
\hline Immunoglobulin G level (g/L) & 4.84 & 4.04 & 6.28 & 6.13-12.95 \\
\hline Immunoglobulin M level (g/L) & 0.45 & 0.49 & 0.57 & $0.53-3.34$ \\
\hline Immunoglobulin A level (g/L) & 2.74 & 2.48 & 3.46 & $0.70-3.12$ \\
\hline Protein electrophoresis & $\begin{array}{l}\text { Low albumin and protein; } \\
\text { otherwise normal }\end{array}$ & $\begin{array}{l}\text { Low proteins; pattern } \\
\text { suggests MGUS lambda }\end{array}$ & - & - \\
\hline Lactulose/mannitol $^{\dagger}$ & - & - & 0.072 & $<0.020$ \\
\hline Sucrose ${ }^{\ddagger}(\mathrm{ng} / \mathrm{mL})$ & - & - & 554 & $<80$ \\
\hline HLA typing & - & - & A2/A32 B/BW6 & - \\
\hline Endomysial antibody & - & - & Negative & - \\
\hline
\end{tabular}

${ }^{*}$ Indicative of functional or true asplenia; ${ }^{\dagger}$ Lactulose/mannitol permeability study; ${ }^{\ddagger}$ Sucrose permeability study. HLA Human leukocyte antigen; MGUS Monoclonal gammopathy of undetermined significance; VDRL Venereal Disease Research Laboratory

We present the first documented case of a patient with presumed celiac sprue who developed NGUJI that was treated successfully with azathioprine.

\section{CASE PRESENTATION}

A 56-year-old Caucasian woman presented with diarrhea and weight loss. Her stools were bulky, floating and pale. She had been thin all her life but was now feeling weak and losing weight despite adequate food intake. She had no history of abdominal pain or vomiting. Medical history included recurrent duodenal ulcers (documented on a barium study 10 years before presentation) and osteoarthritis. Her only medication was amitriptyline for fibromyalgia. Physical examination demonstrated an alert woman weighing $50 \mathrm{~kg}$ and $1.67 \mathrm{~m}$ tall. Other than muscle wasting, there were no abnormalities on examination. Findings of low hemoglobin, low iron, Howell-Jolly bodies on peripheral blood smear, elevated $24 \mathrm{~h}$ fecal fat, low magnesium and low albumin (Table 1) led to a presumptive diagnosis of celiac disease. A barium study showed diffuse edema of the small bowel. A small bowel biopsy (Figure 1) was consistent with the diagnosis of celiac disease, and the patient was placed on a gluten-free diet.

Despite a temporary improvement, she relapsed and was started on prednisone $20 \mathrm{mg} /$ day with resolution of symp- toms. Over the next 10 years, she remained dependent on steroids at doses ranging from 7.5 to $20 \mathrm{mg} /$ day. Despite prednisone therapy, she relapsed again and was hospitalized for weight loss, diarrhea and abdominal pain. Laboratory investigations are shown in Table 1 . An upper gastrointestinal barium study showed a duodenal ulcer and mucosal thickening with slight irregularities on the surface of the mucosa in the jejunum. Serum gastrin was $42 \mathrm{ng} / \mathrm{L}$ (normal 0 to $100 \mathrm{ng} / \mathrm{L}$ ). She was not taking potassium supplements or nonsteroidal anti-inflammatory medications. A computerized tomography scan demonstrated fluid-filled loops of small bowel, with enhancement of the wall of the bowel loops suggesting inflammation. An indium-labelled white blood cell scan showed diffuse, abnormal accumulation of radioactivity within the small bowel $4 \mathrm{~h}$ after injection. At gastroscopy, multiple small bowel ulcerations were visualized distal to the duodenum and were biopsied. Histology consisted of slight villous atrophy, inflammatory infiltration of the lamina propria and areas of ulceration of the villi.

The patient was started on TPN, and her prednisone dose was increased to $30 \mathrm{mg} /$ day. To exclude the possibility of lymphomatous disorder, a laparotomy was performed. Several enterostomies were done intraoperatively in edematous, thickened small bowel, but only diffuse small bowel ulceration was seen with no evidence of lymphoma. A $4.5 \mathrm{~cm}$ seg- 


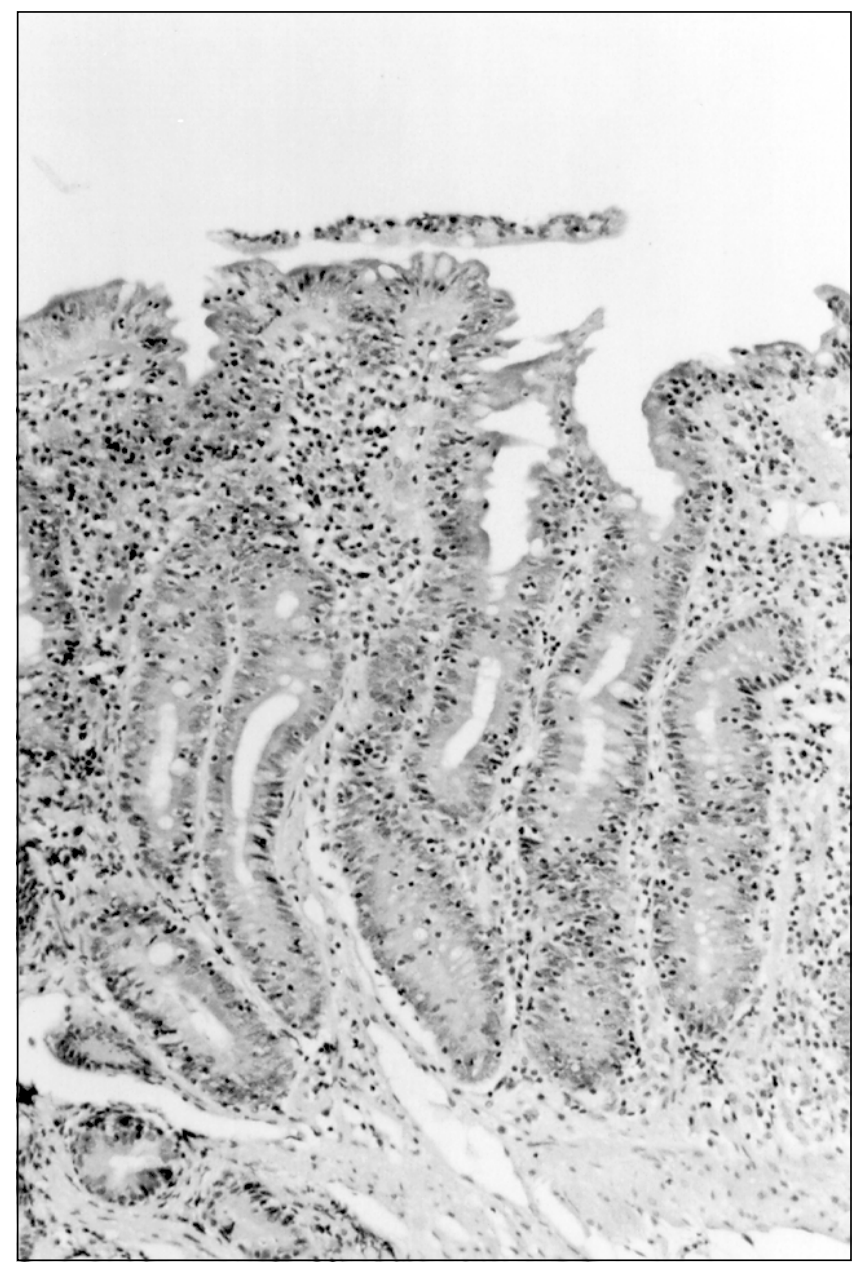

Figure 1) Small bowel biopsy depicting partial villous atrophy, intraepithelial lymphocyte infiltration and crypt hyperplasia

ment of jejunum was resected and showed multiple small $(0.5 \mathrm{~cm})$ mucosal ulcerations extending through the muscularis mucosa into the underlying submucosa (Figure 2).

Azathioprine $50 \mathrm{mg} /$ day was given in addition to prednisone $30 \mathrm{mg} /$ day. The patient remained on azathioprine for the next 42 months with marked improvement in her clinical and biochemical profile (see Table 1). Her hemoglobin, carotene and albumin normalized, and an indium scan and enteroscopy were normal. She was able to taper the prednisone to $7.5 \mathrm{mg} /$ day and subsequently discontinue the azathioprine. Now, eight years following diagnosis of NGUJI, she is asymptomatic while receiving only vitamin D, calcium and prednisone $7.5 \mathrm{mg} /$ day and maintaining a gluten-free diet.

\section{DISCUSSION}

Because of the histological (villous atrophy) and clinical (malabsorption) similarities, NGUJI is often considered to be a form of gluten-sensitive enteropathy. In many cases, the disorder appears to develop in compliant celiac patients with stable disease, but in other cases, the disorder occurs de novo, ie, in people with no known pre-existing disease. This leads some investigators to believe that it is a completely separate

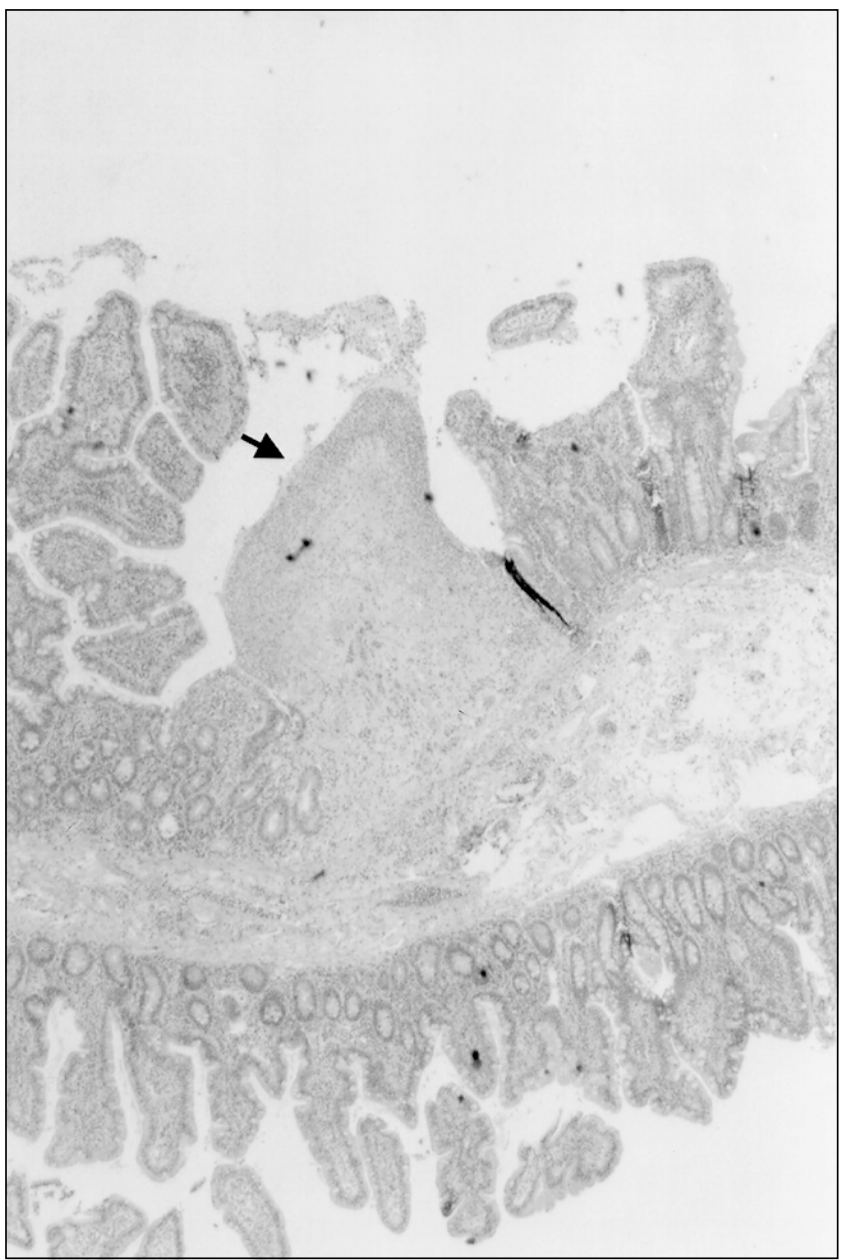

Figure 2) Full-thickness specimen demonstrating ulceration (arrow) in proximal jejunum

entity from celiac disease (6). The patient described in the present study had abnormal sucrose and lactulose/mannitol permeability studies indicative of a small bowel disorder (7-9) but lacked both endomysial antibodies and the typical human leukocyte antigen typing, giving support to the argument that her disorder is different from celiac sprue (10).

Of 70 previously reported patients with NGUJI, $51 \%$ had an underlying disease (6), the most common being celiac disease. The differential diagnosis of NGUJI includes hypogammaglobulinemia, Zollinger-Ellison syndrome, AIDS, Crohn's disease, ischemia, lymphoma, drug toxicity (eg, potassium tablets or nonsteroidal anti-inflammatory medications) and vasculitis $(11,12)$. This patient had normal immunoglobulins; a normal gastrin level; a negative HIV test; no granulomata on her full-thickness biopsies; and no evidence of ischemia, lymphoma or vasculitis. She was not taking potassium or nonsteroidal anti-inflammatory medications. These facts support the diagnosis of NGUJI.

The pathogenesis of this disorder is unknown but it is presumably immunologically based involving antibodies with broad antiepithelial cell specificity, which leads to increased synthesis of immunoglobulin $\mathrm{A}$, which is refractory to gluten withdrawal (10). The use of prednisone to treat NGUJI dates 
back to $1967(1,13)$. The reported results using prednisone in small case series have been conflicting, with a $15 \%$ long term response reported by Baer et al (2) and a 78\% long term benefit reported recently by Ruan et al (6). The benefit of corticosteroids may be related to suppression of elevated immunoglobulin A levels that are refractory to gluten withdrawal (unlike celiac patients without NGUJI) (10). The overall mortality rate is $50 \%$ to $75 \%(2,6)$.

There are no previous reports of using azathioprine in the

\section{REFERENCES}

1. Bayless T, Kapelowitz R, Shelley W, Ballinger W, Hendrix T. Intestinal ulceration: a complication of celiac disease. N Engl J Med 1967;276:996-1002.

2. Baer A, Bayless T, Yardley J. Intestinal ulceration and malabsorption syndromes. Gastroenterology 1980;79:754-65.

3. Hillman $H$. Intestinal malabsorption with subtotal villous atrophy unresponsive to a gluten-free diet but responding to immunosuppressive therapy. Med J Aust 1972;2:82-4.

4. Bernstein $E$, Whitington P. Successful treatment of atypical sprue in an infant with cyclosporine. Gastroenterology 1988;95:199-204.

5. Longstreth G. Successful treatment of refractory sprue with cyclosporine. Ann Intern Med 1993;119:1014-6.

6. Ruan E, Komorowski R, Hogan W, Soergel K. Nongranulomatous chronic idiopathic enterocolitis: clinicopathologic profile and response to corticosteroids. Gastroenterology 1996;111:629-37.

7. Meddings J, Sutherland L, Byles N, Wallace J. Sucrose: A novel permeability marker for gastroduodenal disease. Gastroenterology 1993;104:1619-26.

8. Dawson D, Lobley R, Burrows P, Notman J, Mahon M, Holmes R. management of refractory NGUJI. This patient had required high dose prednisone for only partial relief of symptoms, and the long term side effect profile of corticosteroids is ominous - the use of azathioprine was therefore elected. Her symptoms, biochemical markers and radiological studies all demonstrated marked improvement with azathioprine. Perhaps, through $\mathrm{T}$ helper cell inhibition $(5,14)$, azathioprine played a vital role in suppressing the inflammatory response in this patient with NGUJI.

Changes in jejunal permeability and passive permeation of sugars in intestinal biopsies in coeliac disease and Crohn's disease. Clin Sci 1988;74:427-31.

9. Chadwick V, Philips S, Hofmann A. Measurements of intestinal permeability using low molecular weight polyethylene glycols (PEG 400): application to normal and abnormal permeability states in man and animals. Gastroenterology 1977;73:247-52.

10. Strober W, Falchuk Z, Rogentine G, Nelson D, Klaeveman H. The pathogenesis of gluten sensitive enteropathy. Ann Intern Med 1996;83:242-56.

11. Robertson D, Dickson M, Scott B, Simpson F, Losowsky M. Small intestinal ulceration: diagnostic difficulties in relation to coeliac disease. Gut 1983;24:565-74.

12. Freeman M, Cho S. Nongranulomatous ulcerative jejunoileitis. Am J Gastroenterol 1984;79:446-9.

13. Davidson A. Recurrent benign ileal ulcer occurring with coeliac syndrome. BMJ 1969;3:341.

14. Hamilton J, Chambers R, Wynn-Williams A. Role of gluten, prednisone, and azathioprine in non-responsive coeliac disease. Lancet 1976;i:1213-6. 


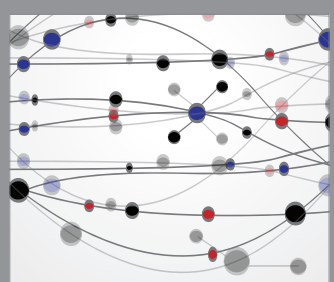

The Scientific World Journal
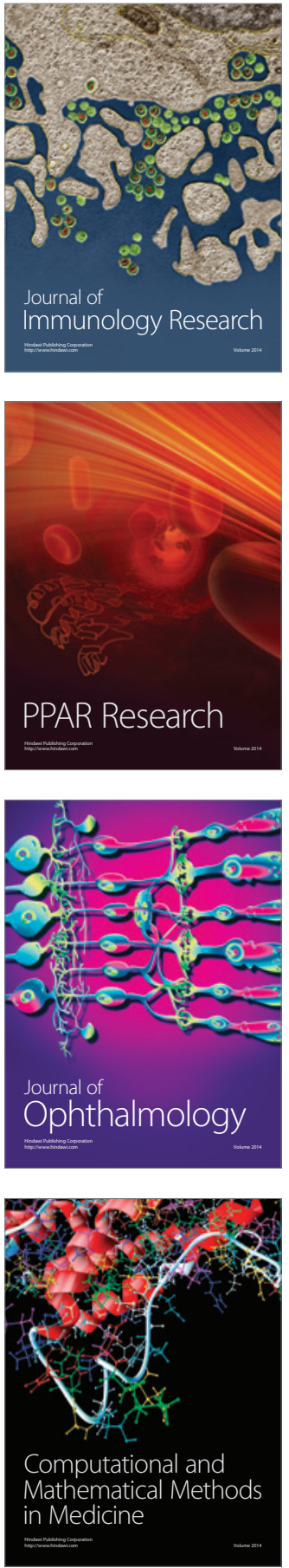

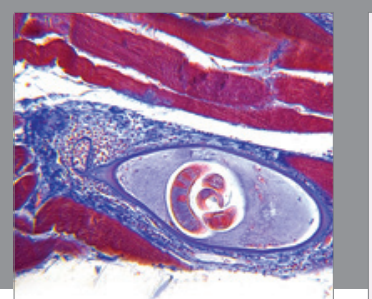

Gastroenterology Research and Practice

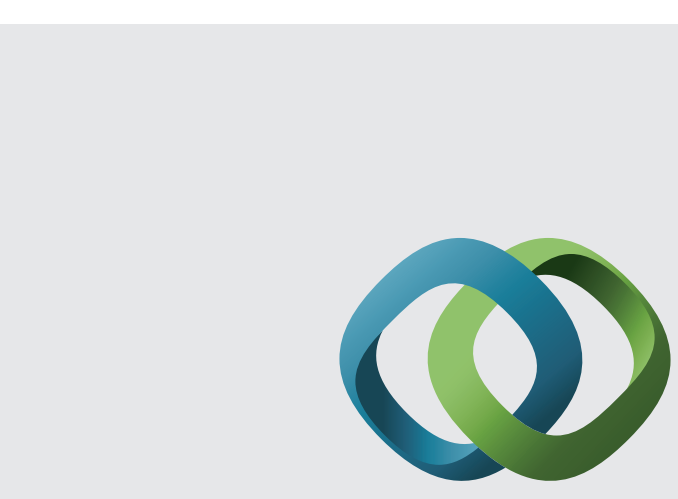

\section{Hindawi}

Submit your manuscripts at

http://www.hindawi.com
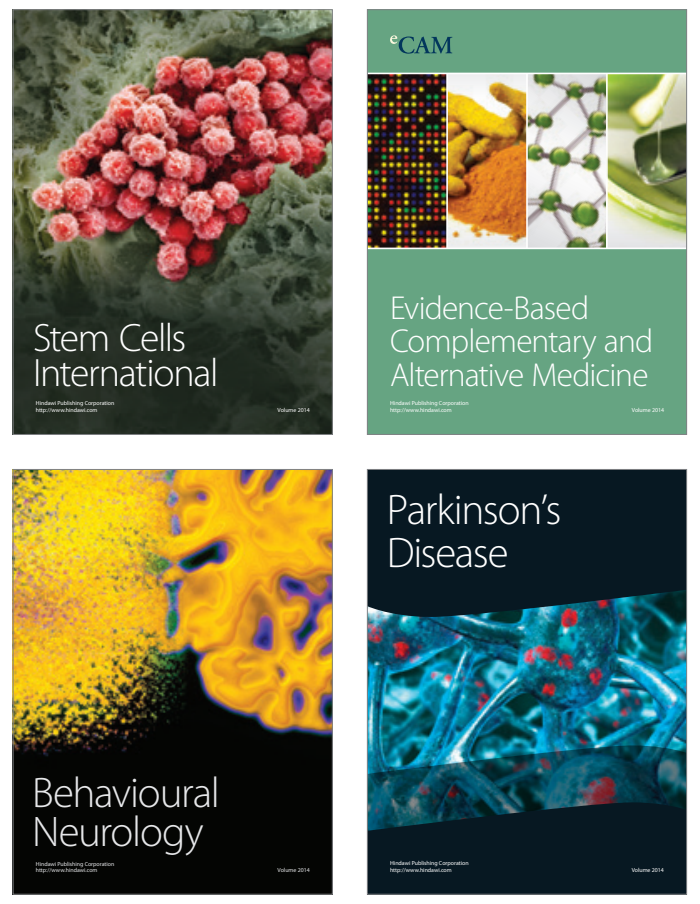
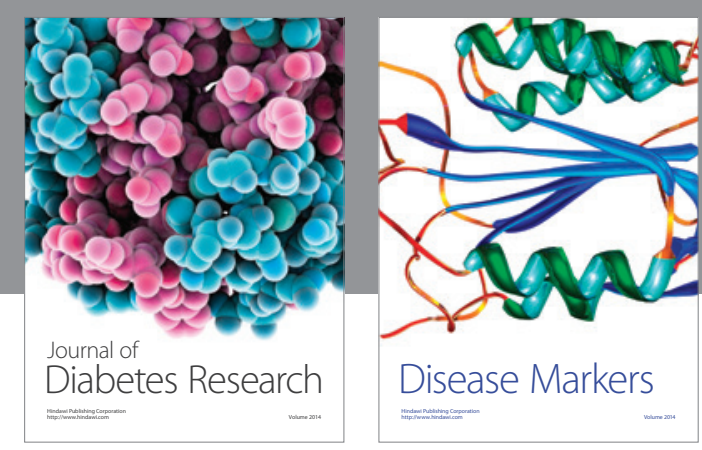

Disease Markers
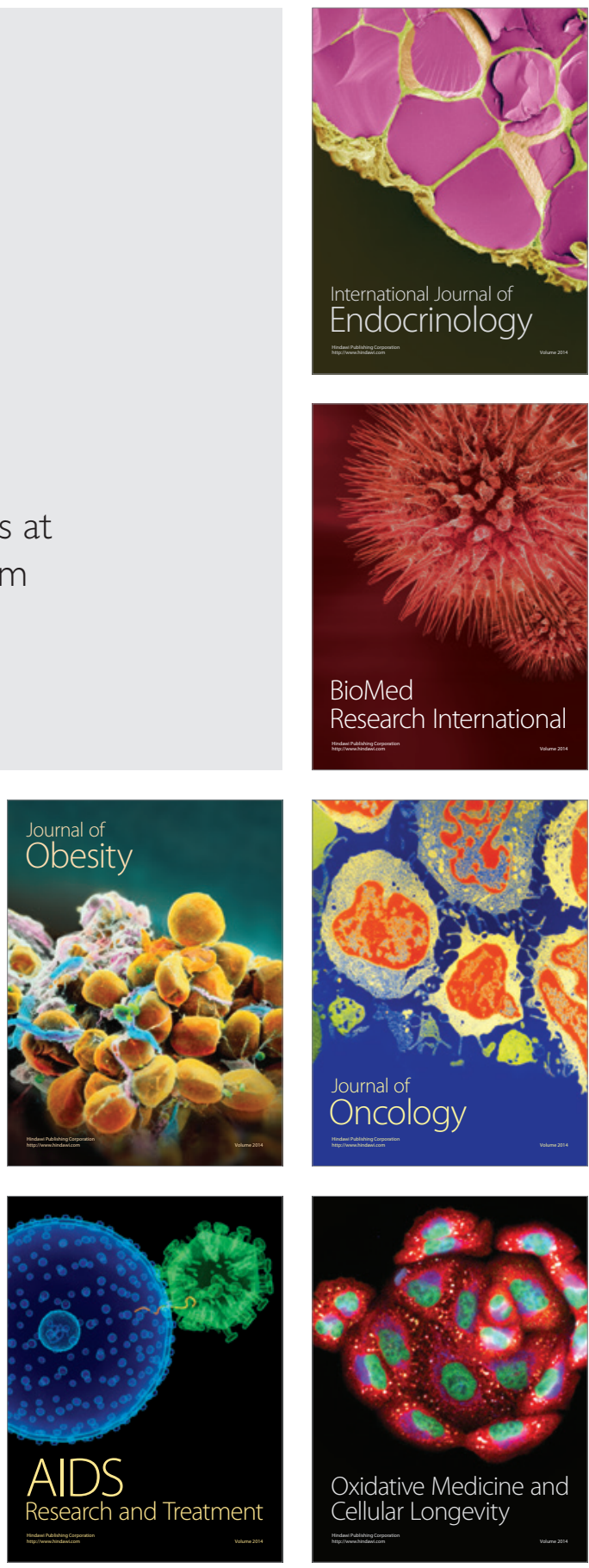